\title{
Helping Underrepresented Students Succeed in AP CSA and Beyond
}

\author{
Barbara Ericson \\ Georgia Institute of Technology \\ 801 Atlantic Drive \\ Atlanta, GA, 30332 \\ ericson@cc.gatech.edu
}

\author{
Tom McKlin \\ The Findings Group \\ 2646 Woodridge Dr. \\ Decatur, GA 30033 \\ tom@thefindingsgroup.org
}

\begin{abstract}
Rise Up 4 CS was created at Georgia Tech in the spring of 2013 to help African American students succeed in their Advanced Placement (AP) Computer Science A (CSA) high school course and on the exam. The AP CSA course is intended to be equivalent to a college level CS1 course. In the fall of 2014, Sisters Rise Up 4 CS was also created to help female students succeed. Rise Up (RU) and Sisters Rise Up (SRU) both offer remote and in-person help sessions led by undergraduate students, who serve as near-peer role models. The long-term goal of these projects is to attract more underrepresented students to computing careers by increasing their self-efficacy. Self-efficacy is the belief that one can succeed in a particular task or field. Thanks to generous support from Google, RU and SRU have been offered at several other colleges and universities as well. This paper summarizes the results from spring 2013 to summer 2016, reports on an alumni survey answered by $68(32 \%)$ of the 211 alumni, and includes excerpts from five semistructured interviews. The majority (63\%) of the alumni survey respondents, who are in college, are majoring in computing. A similar percentage of the alumni who are still in high school intend to major in computing $(62 \%)$. When asked about the programs' impact on their career choices and interest in computing, $61 \%$ of respondents indicated that the program increased their interest in computer science and $24 \%$ indicated that it changed their career plans to computing.
\end{abstract}

\section{KEYWORDS}

Advanced Placement (AP); African Americans, Females; SelfEfficacy; Identity; Outreach; Hispanics; URM

\section{ACM Reference format:}

Barbara Ericson and Tom McKlin. 2018. Helping Underrepresented Students Succeed in AP CSA and Beyond, In SIGCSE '18: 49th ACM Technical Symposium on Computer Science Education, Feb. 21-24, 2018, Baltimore, MD, USA. ACM, NY, NY, USA, 6 pages. https://doi.org/10.1145/3159450.3159517

Permission to make digital or hard copies of all or part of this work for personal or classroom use is granted without fee provided that copies are not made or distributed for profit or commercial advantage and that copies bear this notice and the full citation on the first page. Copyrights for components of this work owned by others than ACM must be honored. Abstracting with credit is permitted. To copy otherwise, or republish, to post on servers or to redistribute to lists, requires prior specific permission and/or a fee. Request permissions from Permissions@acm.org. SIGCSE '18, February 21-24, 2018, Baltimore, MD, USA

(C) 2018 Association for Computing Machinery.

ACM ISBN 978-1-4503-5103-4/18/02...\$15.00

https://doi.org/10.1145/3159450.3159517

\section{INTRODUCTION}

The average number of computer science majors at doctoral granting institutions has more than doubled since 2011 [11]. However, women, and Underrepresented Minorities (URM) are still not well represented in computing. URM includes African Americans, Hispanics, Native Americans, and Pacific Islanders. Women earned only $16 \%$ of computer science bachelor degrees awarded at doctoral-granting institutions in 2015, though they are roughly half the population [4; 10]. In 2015, URM students earned $13 \%$ of computer science bachelor degrees at doctoral granting institutions, though they are roughly $30 \%$ of the population $[4 ; 10]$.

Interest in computing is also increasing at the high school level. The number of AP CSA exams taken nationwide over the last five years has more than doubled from $2012(24,782)$ to 2016 $(54,379)$ [2]. However, women, African Americans, and Hispanics are still not well represented as shown in Table 1. Females were less than a quarter of all AP CSA exam takers in 2016 and had a lower pass rate on average than males. African Americans, who are approximately $13 \%$ of the U.S. population, were only $3.7 \%$ of exam takers in 2016 and their average pass rate was nearly half that of Caucasian students [10].

Table 1: National Data for AP CSA Exam Takers for 2016

\begin{tabular}{|l|lll|}
\hline Gender & Number & Percent & Pass Rate \\
\hline Females & 12,642 & $23.2 \%$ & $60.7 \%$ \\
\hline Males & 41,737 & $76.8 \%$ & $64.7 \%$ \\
\hline Ethnicity & & \\
\hline African American & 2,027 & $3.7 \%$ & $33.2 \%$ \\
\hline Hispanic & 6,256 & $11.5 \%$ & $41.5 \%$ \\
\hline Asian & 15,913 & $29.3 \%$ & $72.7 \%$ \\
\hline Caucasian & 26,698 & $49.1 \%$ & $65.7 \%$ \\
\hline
\end{tabular}

Failing the AP CSA exam could decrease underrepresented students' confidence in their ability to succeed in a computing career. Research has shown that believing that you can succeed is a key factor in choosing a career [17]. Women and URM are already at risk for low self-efficacy in computing because the prevailing stereotype of a computer scientist is a White or Asian male [23; 34]. High achieving high school girls often turn away from STEM subjects, such as math in high school, because they tend to believe that if they are finding a subject difficult then they do not have the ability to do well in the subject $[16 ; 36]$. 
Nearly half (46\%) of the students who dropped an introductory course in computing in college felt that it was too challenging and $75 \%$ of those who dropped were female [24]. Prior research has shown that females are more likely to succeed in collegelevel computer science courses if they had prior experience, such as an AP CSA course in high school [5]. Helping more underrepresented students succeed in AP CSA could increase the diversity of the field.

Ericson at Georgia Tech created RU and SRU to help African American and female students in Georgia succeed in their AP CSA course and on the exam $[19 ; 22 ; 20]$. This paper summarizes the results from spring 2013 to summer 2016, presents the findings from an alumni survey, and contains excerpts from alumni semi-structured interviews. Our research questions were: 1) To what extent did the alumni persist or intend to persist in post-secondary computing? 2) What role did RU and SRU play in developing their interest and enabling them to persist in computing?

\section{RELATED RESEARCH}

Harvey Mudd [3] and Carnegie Mellon University [25] have greatly increased their percentage of females in undergraduate computer science, but the majority of institutions have not [4]. Ways to attract underrepresented students to computing and to help them succeed in computing include computing summer programs $[1 ; 14 ; 21 ; 30 ; 39]$, bridge programs [38], and revising the first course in computing at the college level [12]. While results from many of these projects have been encouraging, the long-term effects are not known. Given the limitations of space, this section will only cover efforts that targeted high school students and prepared them to pass an AP course and exam. This section also describes other research, in self-efficacy and how people learn, which informed the design of RU and SRU.

\subsection{Glitch}

The three-year Glitch project successfully increased African American male high school students' interest in computing careers by paying them to be game testers and by teaching them computing concepts [13]. When the project started only $20 \%$ of the participants were interested in a career in computing. One year after the project ended, $65 \%$ of the participants who were attending college $(n=25)$ had pursued some form of postsecondary computing. Project features included exposure to a college campus, a community of practice, competitions, and undergraduate students as near-peer role models who led the instruction in computing concepts.

\subsection{Advanced Placement Incentive Program}

The Advanced Placement Incentive Program (APIP), run by AP Strategies, increases the number of students who take and pass Advanced Placement exams by offering extra help sessions, teacher professional development, and financial incentives for both teachers and students [29]. The financial incentives range from $\$ 100$ to $\$ 500$ for each passing score (three or higher). More females and underrepresented minorities are taking AP courses at APIP participating schools and more are passing the exams. However, these programs are costly. The National Math and Science Initiative (NMSI) has replicated this program [40], and has had similar results.

\subsection{Research on Self-Efficacy}

Self-efficacy is one's belief in one's ability to succeed at a particular task or subject [6]. Self-efficacy is very important in career selection [17]. People quickly remove career fields from consideration if they do not think they can succeed in them [6]. There is a significant correlation between self-efficacy and interest in a field [33]. High self-efficacy results in more persistence in technical or scientific majors than low selfefficacy [32]. Females have a lower self-efficacy in computing than males [26; 35], which may be an important factor in their underrepresentation in computing. Self-efficacy in a field can be improved by success [15], exposure to similar role models in the field [7], and social encouragement [6]. Research has shown that encouragement and positive feedback from instructors raises self-efficacy for minority students for scientific fields [28].

\subsection{Research from the Learning Sciences}

One of the challenges for RU and SRU was how to help underrepresented students succeed in their AP CSA course and on the exam. The exam consists of 40 multiple-choice questions and four free response questions with multiple parts that require the students to write Java code on paper. We incorporated spaced practice, worked examples plus practice, and a community of practice to provide social support and encouragement.

Practice is very important in developing expertise [9] and spaced practice (i.e. practice over a length of time) is better than massed practice, (cramming for an exam) for long-term retention [8]. One of the ways to improve the efficiency of learning is through worked examples, especially with interleaved practice problems $[42 ; 43]$. A worked example is an expert's detailed solution to a problem. A community of practice is a group of people interacting regularly that share a common interest or goal [44]. Communities of practice have been shown to improve learning and the formation of identity in a field [31].

\section{SUMMARY OF RESULTS - 2013 TO 2016}

RU and SRU incorporated undergraduate student near peer role models who lead the help sessions, exposure to a college campus, and a community of practice from Glitch [13]. The undergraduate students were paid an hourly rate. We hired three undergraduate students per project. Most of the undergraduate student leaders were underrepresented in computing (African American, Hispanic, or female), but not all.

RU and SRU originally replicated the student incentives from APIP [29], but reduced the cost by offering smaller incentives (\$100) and by offering remote and in-person help sessions. RU and SRU tried to improve the participants' self-efficacy in computing by helping the students succeed in the AP CSA course, through exposure to near peer role models, and through 
social support in a community of practice. The project provided spaced practice through one-hour weekly remote and three-hour monthly in-person help sessions and through the use of an interactive ebook, which was developed for the project, with worked examples and interleaved practice problems [18].

RU has been offered at Georgia Tech every year since January 2013 [19;22]. Based on feedback from the first cohort we started in the fall rather than the spring after the first year. SRU started in the fall of 2014 and has been offered at Georgia Tech every year since then [20]. Table 2 shows the percentage of participants who completed the project by attending at least four help sessions, which has varied from $35 \%$ to $76 \%$. The pass rate for completers has varied from a low of $31 \%$ to a high of $64 \%$, but is usually higher than the pass rate for that same group in Georgia as shown in Table 2. For the first three years we paid participants who attended a required number of help sessions and passed the exam with a score of three or higher $\$ 100$. In years two and three we also paid participants an additional $\$ 100$ for attending the required number of help sessions (4). Only a few of the participants mentioned the payments as a reason for joining or completing the project, and some who qualified for the payment never filled out the paperwork to receive it. To test the need for these monetary payments, we did not include them in SRU. As seen in Table 2, SRU had similar completion and pass rates to RU. We stopped offering monetary incentives after the 2014-2015 academic year, which reduced the cost of the project.

Table 2: Rise Up and Sisters Rise Up in Georgia

\begin{tabular}{|l|llll|}
\hline $\begin{array}{l}\text { Georgia RU } \\
\text { and SRU }\end{array}$ & N & $\begin{array}{l}\text { Number } \\
\text { Comp. }\end{array}$ & $\begin{array}{l}\text { \# Comp. } \\
\text { Passed }\end{array}$ & $\begin{array}{l}\text { GA \% } \\
\text { Passed }\end{array}$ \\
\hline RU Spr 13 & 27 & $14(52 \%)$ & $9(64 \%)$ & $21.7 \%$ AA \\
\hline RU 13-14 & 33 & $18(55 \%)$ & $7(39 \%)$ & $22.6 \%$ AA \\
\hline RU 14-15 & 21 & $16(76 \%)$ & $5(31 \%)$ & $31.6 \%$ AA \\
\hline RU 15-16 & 19 & $11(58 \%)$ & $7(64 \%)$ & $34.5 \%$ AA \\
\hline SRU 14-15 & 21 & $12(57 \%)$ & $6(50 \%)$ & $48.3 \% \mathrm{~F}$ \\
\hline SRU 15-16 & 20 & $7(35 \%)$ & $3(43 \%)$ & $51.3 \% \mathrm{~F}$ \\
\hline
\end{tabular}

Thanks to support from Google, we have been able to offer RU and SRU at other locations as shown in Table 3. Bowie State University offered RU in Maryland (MA) in the spring of 2014 and again during 2014-2015 [22]. However, due to administrative problems, they did not collect all the scores for the participants from 2014-2015. Florida International University offered RU in the spring of 2015 for African Americans, however not many African American enrolled. During the 2015-2016 academic year they allowed any underrepresented student to enroll and had mostly Hispanic students. Westminster College in Utah ran SRU in the spring of 2016. However, not many female students enrolled as seen in Table 3. These replication projects had high pass rates for completers, especially when compared to the pass rates for the targeted underrepresented group in the that state.
Table 3: Rise Up and Sisters Rise Up in Other States

\begin{tabular}{|l|rlll|}
\hline $\begin{array}{l}\text { Location and } \\
\text { Year }\end{array}$ & N & \# Comp. & $\begin{array}{l}\text { \# Comp. } \\
\text { Passed }\end{array}$ & $\begin{array}{l}\text { \% Passed } \\
\text { in State }\end{array}$ \\
\hline MA RU Spr 14 & 22 & $9(41 \%)$ & $6(67 \%)$ & $30.2 \%$ AA \\
\hline MA RU 14-15 & 19 & $6(31.6 \%)$ & 1 score rec. & $37.9 \%$ AA \\
\hline FL RU Spr 15 & 6 & $3(50 \%)$ & $3(100 \%)$ & $25.7 \%$ AA \\
\hline FL RU 15-16 & 14 & $8(57 \%)$ & $7(88 \%)$ & $41.3 \%$ H \\
\hline UT SRU Spr 16 & 8 & $2(25 \%)$ & $2(100 \%)$ & $68.8 \%$ F \\
\hline
\end{tabular}

Participants have shown statistically significant attitude changes from pre to post and have reported an increase in interest in a career in computing $[19 ; 22 ; 20]$. Several participants have credited RU or SRU with helping them succeed in their AP CSA courses and on the exam. Even students who did not pass the exam have credited RU and SRU with sustaining or increasing their interest in a computing career.

One of the participants from Florida International University's Rise Up 4 CS in 2015-2016 was a $9^{\text {th }}$ grade Hispanic male. He chose AP CS A because he thought the course "sounded cool." However, he found the first few assignments uninteresting, felt that he was "just taking down notes," and became lost when object-oriented programming was introduced. He got further behind when he went on vacation with his family and lost his flash drive with his assignments. By the end of the first quarter his grade had dropped to a D. His teacher recommended joining RU. He participated in the twice-weekly webinars and a tutor offered individualized support. He passed the exam with a 5 , the highest possible score. This demonstrates how easy it is for a student to get behind in AP CSA and how valuable extra help can be.

\section{LONG TERM IMPACT IN GEORGIA}

One way to measure the long-term impact of RU is examine the AP CSA data for Georgia. Table 4 shows the number of African American exam takers in Georgia from 2012 to 2016, the number who passed the exam, the pass rate in Georgia, and the pass rate nationally. Notice that the number of African American students passing the exam has more than doubled since 2013 and the pass rate has increased each year since we started RU in the spring of 2013. We can not claim that this increase is due to RU, but we have had participants who say that they would not have passed the exam without the project. The pass rate for African Americans in Georgia was below the national average when we started in 2012, but exceeded the national average for African Americans in 2016.

Table 4: African American data from 2012 to 2016

\begin{tabular}{|l|llll|}
\hline Year & $\begin{array}{l}\text { GA \# } \\
\text { AA }\end{array}$ & $\begin{array}{l}\text { GA \# AA } \\
\text { Passed }\end{array}$ & $\begin{array}{l}\text { GA AA } \\
\text { Pass Rate }\end{array}$ & $\begin{array}{l}\text { National AA } \\
\text { Pass Rate }\end{array}$ \\
\hline 2012 & 137 & 22 & $16.1 \%$ & $27.3 \%$ \\
\hline 2013 & 129 & 28 & $21.7 \%$ & $35.6 \%$ \\
\hline 2014 & 155 & 35 & $22.6 \%$ & $33.4 \%$ \\
\hline 2015 & 174 & 55 & $31.6 \%$ & $37.7 \%$ \\
\hline 2016 & 174 & 60 & $34.5 \%$ & $33.2 \%$ \\
\hline
\end{tabular}


More females in Georgia have been taking the AP CSA exam and passing it since we started SRU in the fall of 2014 as shown in Table 5. Note that the number of females passing the exam in Georgia has doubled from 2014 to 2016. The percentage of females that pass the exam in Georgia is still less than the national average, but it has increased each year since we started SRU.

Table 5: Female data from 2014 to 2016 in Georgia

\begin{tabular}{|l|llll|}
\hline Year & $\begin{array}{l}\text { GA \# } \\
\text { Fem. }\end{array}$ & $\begin{array}{l}\text { GA \# Fem. } \\
\text { Passed }\end{array}$ & $\begin{array}{l}\text { GA Fem. } \\
\text { Pass Rate }\end{array}$ & $\begin{array}{l}\text { National } \\
\text { Fem. Pass } \\
\text { Rate }\end{array}$ \\
\hline 2014 & 285 & 119 & $41.8 \%$ & $57.1 \%$ \\
\hline 2015 & 315 & 152 & $48.3 \%$ & $60.6 \%$ \\
\hline 2016 & 464 & 238 & $51.3 \%$ & $60.7 \%$ \\
\hline
\end{tabular}

We can not claim that this increase in females taking and passing the AP CSA exam is due to SRU, since the number of females passing the exam is far higher than the number of participants in SRU. However, we send out letters to underrepresented students in Georgia who do well on the PSAT to encourage them to take AP CSA and to let them know about RU and SRU. Some of our female participants have told us that the letter convinced them to try AP CSA, since they knew they could get help from SRU. Participants have credited SRU with increasing their interest in computing and their ability to succeed in their course and on the exam [20]. We also hope that these projects have a ripple effect by showing that underrepresented students can succeed in computing.

\section{ALUMNI SURVEY}

In February of 2017, the 211 alumni of RU and SRU were emailed a request to complete an online survey. Those who completed the survey were entered into a drawing for a prize worth $\$ 150$. Responses were received from 68 program alumni, for a $32.2 \%$ response rate. This rate is slightly higher than the typical response rate (25-30\%) for emailed surveys [45]. Fig. 1 shows the percentage of survey respondents by their year of participation and location.
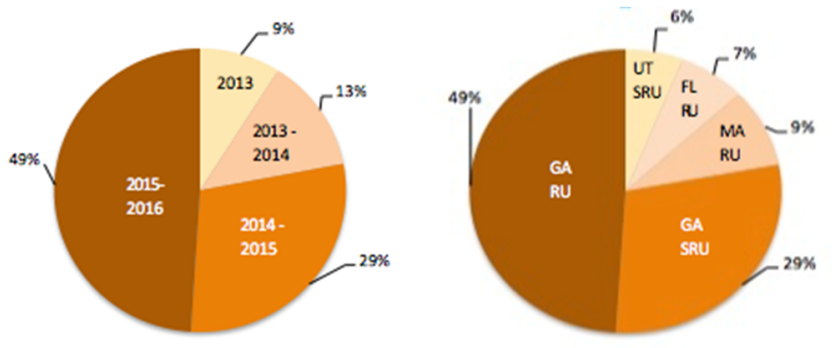

Figure 1: Percentage of survey respondents by year and location

Of those responding to the survey, $42(62 \%)$ were high school graduates while the remaining $26(38 \%)$ were still enrolled in high school. Of those who had graduated from high school 41
(98\%) were currently attending college. The remaining student was not enrolled in college for health reasons. Table 6 provides the number and percentage of survey respondents for each ethnicity and gender as well as the percentage of alumni in each category.

Table 6: Survey Respondents by Race and Gender

\begin{tabular}{|l|lll|}
\hline Ethnicity & \# Resp. & \% Resp. & \% Alumni \\
\hline African American & 42 & $62 \%$ & $74 \%$ \\
\hline Asian & 14 & $21 \%$ & $11 \%$ \\
\hline Caucasian & 5 & $7 \%$ & $8 \%$ \\
\hline Hispanic & 5 & $7 \%$ & $6 \%$ \\
\hline Two or More Races & 2 & $3 \%$ & $1 \%$ \\
\hline Gender & \multicolumn{4}{l}{} \\
\hline Female & 37 & $55 \%$ & $46 \%$ \\
\hline Male & 31 & $45 \%$ & $54 \%$ \\
\hline
\end{tabular}

The majority of the survey respondents, who were enrolled in college, were majoring in computing $(63 \%, n=26)$. One student was minoring in computing. Of the students who were enrolled in college and not majoring or minoring in computing, 6 had taken a computing course in college, and 7 had used programming in their major. Of the students who were still in high school $(n=26), 62 \%$ report that they intend to major in computing.

The majority of survey respondents $(61 \%, n=38)$ indicated that the program increased their interest in computer science. Several of the open-ended comments showed how the participants felt that the project improved their self-efficacy in computing. "It made it easier and more interesting, I felt better when doing it and my confidence in my abilities grew my interest in CS." A female alumnus wrote, "I thought CS was too hard or not for me before joining SRU." Another alumnus wrote, "It showed me that I can do well in this field, it just takes hard work and determination."

Alumni were asked if RU or SRU changed their career plans. The majority of them $(n=45,73 \%)$ reported that it had not changed their career plans, however $27 \%(n=17)$ reported that it did. Two of these students said that it helped them realize that they did not want to major in computing. One of these students said, "the complexities of coding scared me away". This student went on to write, "I would like to pick up coding again because I think it's a very effective skill in the work force." The remaining $24 \%(n=15)$ of the alumni reported that it changed their career plans to include computing. One alumni wrote, "I was planning to go into prosthetic research with Biomedical Engineering, but I realized that Computer Science is much more fitting for me." Another wrote, "This program encouraged me to go into the computing field; it was a huge component of my decision."

\section{INTERVIEWS WITH ALUMNI}

In order to gain a deeper understanding of the ways that RU and SRU impacted our alumni, we held semi-structured interviews with five of them. Three were female and two were male. Three were African American, one was Asian, and one was Caucasian. 
We interviewed one student from spring 2013, one from 20132014, one from 2014-2015, and two from 2015-2016.

Students told us that they were able to improve their understanding of computing concepts with the help of RU and SRU, even if their teachers were not knowledgeable. "She didn't know the material herself. So, everyone in the class was confused. By then, like I was getting 100s on free responses and stuff and everyone was getting 30s. They're like, 'How do you know this stuff?" Another alumnus said, "I had a teacher who didn't take computer science and really didn't know anything about it. So, he did the best he could with it. But at the end of the day, thankfully to Rise Up, I was able to kind of go back and look and try to cram so much stuff in just to kind of get a better understanding of everything."

Even students who were already interested in computing were discouraged by the difficulty of the AP CSA course [37]. "So, I was like, 'I'm going to love the AP class. I'm going to animate. I'm going to make awesome scenes every day.' We had been working with just Alice (2). In AP, we were working in Alice 3...We actually did a lot of just plain coding, and it was very difficult. So, I definitely needed Project Rise Up... With Rise Up, I liked the one-on-one. I love that there were online sessions so I could join at home, and watch, and type my questions, as well as going in in person and meeting like-minded individuals who either excelled in the program and wanted to see the other ways they could solve equations or were just like me and needed as much help as they could get." This quote shows that this student valued the community of practice.

Alumni said that the undergraduates could relate to their difficulties and help them understand concepts, even more than knowledgeable teachers. "They knew the struggle of trying to understand... That's the problem that my teacher couldn't do, because he knew it, but he didn't know how to teach other people how to know it." The undergraduate students also helped attract students to computing by serving as role models. As one alumni said, "...they exuded enthusiasm for computer science. I mean, meeting people that really love what they're doing really makes you think, 'Oh, maybe I want to be as happy as they are with what they're doing.' And they all seemed to have really cool internships and job opportunities. They just really have cool things going on." One of the proven ways to improve self-efficacy is to see others like yourself succeed [6].

One of the interviews with a female student in SRU was originally feeling a lack of self-efficacy in computing. She was one of only four women taking the course online compared to about 70 males. "I thought computer science was taught more for guys. Like I had one friend that went to a different school taking it, and he seemed to get it easily and had other guys to work with. I was like, 'You know, maybe there's a reason only guys are majoring in this, or mostly guys." After working with SRU she started understanding more and improved. The reaction of her male friend shows how hard it can be for women to overcome the prevalent stereotypes. "So, he knew I was significantly worse at computer science than him at the beginning. Then at one point, I got a better grade than him on an assignment and he's like, 'Oh, did you cheat?' Like he just didn't see that I can figure stuff out and had been learning, which was what I got out of the program." She was understandably annoyed at being accused of cheating. Though this student did not pass the AP CSA exam, she is majoring in computing at Georgia Tech and is one of the undergraduate leaders of SRU.

\section{DISCUSSION}

Prior research had shown that Rise Up and Sisters Rise Up had increased the participants' intent to pursue post-secondary computing studies $[19 ; 22 ; 20]$. However, underrepresented students face stereotypes that can discourage them from pursuing particular careers [41], so it was possible that they might not feel that way a year or more later. Our first research question was to what extent did the alumni persist or intend to persist in post-secondary computing? Over $60 \%$ of the alumni survey respondents are majoring in computing or plan to when they reach college. In addition, $79 \%$ of the respondents who are in college have taken more computing courses.

Our second research question was what role did RU and SRU play in developing their interest and enabling them to persist in computing? The majority (61\%) of the survey respondents credit RU and SRU with increasing their interest in computing and $24 \%$ say that it changed their major to computing. The interviews provide evidence that the projects improved understanding, provided social encouragement through a community of practice, and increased interest through undergraduate role models.

A limitation of this study is that the survey response rate was $32.2 \%$. While higher than we might expect for an email survey, the respondents may not represent the majority of the alumni. Also, nearly half of the respondents were from the 20152016 academic year, so while they intend to continue in computing, that could change. More follow-up studies should be done to verify these results over time.

\section{CONCLUSIONS}

Underrepresented students are especially at risk of failure in introductory computing due to less prior experience and a lack of encouragement [24; 27]. With the enrollment surge at the college level, which has increased class sizes, less help is available for novice students [4]. This means that it is more important than ever for underrepresented students to have prior experience before taking college-level computing courses. This paper provides evidence for the long-term effects of RU and SRU, which help underrepresented students succeed in the AP CSA course and on the exam. It provides evidence that these projects attracted underrepresented students to computing and encouraged them to persist in computing in their post-secondary education by improving their self-efficacy in computing. By helping more underrepresented students succeed in AP CSA we may be able to improve the gender balance in computing and the representation of underrepresented minorities. 


\section{ACKNOWLEDGMENTS}

The funding for RU and SRU came from the National Science Foundation grant CNS-1228352 as well as RISE awards TFR1400363 and TFR14-03256 from Google. We thank the undergraduate students who led RU or SRU in Florida, Georgia, Maryland, and Utah. We also thank the reviewers for their comments, which improved the clarity of the paper.

\section{REFERENCES}

[1] Adams, Joel C., 2007. Alice, middle schoolers \& the imaginary worlds camps. In Proceedings of the 38th SIGCSE technical symposium on Computer science education (Covington, Kentucky, USA, 2007), ACM, 1227418, 307-311.

[2] Advanced Placement Data From 2016, https://research.collegeboard.org/programs/ap/data/participa tion/ap-2016, Accessed 2016, May 20

[3] Alvarado, Christine and Dodds, Zachary, 2010. Women in CS: an evaluation of three promising practices. In Proceedings of the 41st ACM technical symposium on Computer science education (Milwaukee, Wisconsin, USA, 2010), ACM, 1734281, 57-61.

[4] Association, Computing Research, 2017. Generation CS: Computer Science Undergradute Enrollments Surge Since 2006.

[5] Babes-Vroman, Monica, Juniewicz, Isabel, Lucarelli, Bruno, Fox, Nicole, Nguyen, Thu, Tjang, Andrew, Haldeman, Georgiana, Mehta, Ashni, and Chokshi, Risham, 2017. Exploring Gender Diversity in CS at a Large Public R1 Research University. In Proceedings of the 2017 ACM SIGCSE Technical Symposium on Computer Science Education (Seattle, Washington, USA, 2017), ACM, 3017773, 51-56.

[6] Bandura, Albert, 1997. Self-efficacy: The exercise of control. Macmillan.

[7] Barnir, Anat, Watson, Warren E, and Hutchins, Holly M, 2011. Mediation and moderated mediation in the relationship among role models, selfâ efficacy, entrepreneurial career intention, and gender. Fournal of Applied Social Psychology 41, 2, 270-297.

[8] Bjork, Robert A., Dunlosky, John, and Kornell, Nate, 2013. Self-Regulated Learning: Beliefs, Techniques, and Illusions. Annual Review of Psychology 64, 417-444.

[9] Bransford, John D., Brown, Ann L., and Cocking, Rodney R., 2000. How People Learn NATIONAL ACADEMY PRESS, Washington D.C.

[10] Bureau, United States Census, Quick Facts, https://www.census.gov/quickfacts/fact/table/US/PST045216, Accessed 2017, August 27, 2017

[11] Camp, Tracy, Adrion, W. Richards, Bizot, Betsy, Davidson, Susan, Hall, Mary, Hambrusch, Susanne, Walker, Ellen, and Zweben, Stuart, 2017. Generation CS: the growth of computer science. ACM Inroads 8, 2, 44-50.

[12] Cohoon, James P and Tychonievich, Luther A, 2011. Analysis of a CS1 approach for attracting diverse and inexperienced students to computing majors. In Proceedings of the 42nd ACM technical symposium on Computer science education ACM, 165-170.

[13] Disalvo, Betsy, Guzdial, Mark, Meadows, Charles, Perry, Ken, Mcklin, Tom, and Bruckman, Amy, 2013. Workifying games: successfully engaging African American gamers with computer science. In 44th ACM technical symposium on Computer science education (SIGCSE) (Denver, Colorado, USA, 2013), ACM, 317-322.

[14] Doerschuk, Peggy, Liu, Jiangjiang, and Mann, Judith, 2007. Pilot summer camps in computing for middle school girls: from organization through assessment. In Proceedings of the 12th annual SIGCSE conference on Innovation and technology in computer science education (Dundee, Scotland, 2007), ACM, 1268789, 4-8.

[15] Doyle, Eileen, Stamouli, Ioanna, and Huggard, Meriel, 2005. Computer anxiety, self-efficacy, computer experience: An investigation throughout a computer science degree. In Frontiers in Education, 2005. FIE'05. Proceedings 35th Annual Conference IEEE, S2H-3.

[16] Dweck, Carol, 1986. Motivational Processes Affecting Learning. American Psychologist 41, 10, 1040-1048.

[17] Eccles, Jacquelynne, 2009. Who am I and what am I going to do with my life? Personal and collective identities as motivators of action. Educational Psychologist 44, 2, 78-89.

[18] Ericson, Barbara, Java Review Book for the AP CS A exam https://runestone.academy/runestone/static/JavaReview/inde x.html, Accessed 2016, April 25

[19] Ericson, Barbara, Engelman, Shelly, Mcklin, Tom, and Taylor, Ja'quan, 2014. Project rise up $4 \mathrm{CS}$ : increasing the number of black students who pass advanced placement CS A. In Proceedings of the 45th ACM technical symposium on Computer science education (Atlanta, Georgia, USA, 2014), ACM, 2538937, 439-444.
[20] Ericson, Barbara J., Parker, Miranda C., and Engelman, Shelly, 2016. Sister Rise Up 4 CS: Helping Female Students Pass the Advanced Placement Computer Science A Exam. In Proceedings of the 47th ACM Technical Symposium on Computing Science Education (Memphis, Tennessee, USA, 2016), ACM, 2844623, 309-314.

[21] Ericson, Barbara and Mcklin, Tom, 2012. Effective and sustainable computing summer camps. In Proceedings of the 43rd ACM technical symposium on Computer Science Education (Raleigh, North Carolina, USA, 2012), ACM, New York, NY, 289-294.

[22] Ericson, Barbara and Mcklin, Tom, 2015. Helping African American Students Pass Advanced Placement Computer Science: A Tale of Two States. In Research on Equity and Sustained Participation in Engineering, Computing, and Technology (RESPECT) (Charlotte, NC, USA, 2015), IEEE.

[23] Fisher, Allan and Margolis, Jane, 2002. Unlocking the clubhouse: the Carnegie Mellon experience. SIGCSE Bull. 34, 2, 79-83.

[24] Fisher, Lawrence M., 2016. Booming enrollments. Commun. ACM 59, 7, 17-18.

[25] Frieze, Carol and Quesenberry, Jeria, 2015. Kicking Butt in Computer Science: Women in Computing at Carnegie Mellon University. Dog Ear Publishing.

[26] Google and Gallup, 2016. Diversity Gaps in Computer Science: Exploring the Underrepresentation of Girls, Blacks and Hispanics.

[27] Google and Gallup, 2015. Searching for Computer Science: Access and Barriers in U.S. K-12 Education.

[28] Hackett, Gail, Betz, Nancy E, Casas, J Manuel, and Rocha-Singh, Indra A, 1992. Gender, ethnicity, and social cognitive factors predicting the academic achievement of students in engineering. Fournal of counseling Psychology 39, 4 527.

[29] Jackson, C. K., 2010. A little now for a lot later: A look at a Texas Advanced Placement incentive program. Journal of Human Resources 45, 591-639.

[30] Lau, Winnie W.Y., Ngai, Grace, Chan, Stephen C.F., and Cheung, Joey C.Y. 2009. Learning programming through fashion and design: a pilot summer course in wearable computing for middle school students. In Proceedings of the 40th ACM technical symposium on Computer science education (Chattanooga, TN, USA, 2009), ACM, 1509041, 504-508.

[31] Lave, Jean and Wenger, Etienne, 1998. Communities of practice. Retrieved fune 9, 2008.

[32] Lent, Robert W, Brown, Steven D, and Larkin, Kevin C, 1984. Relation of selfefficacy expectations to academic achievement and persistence. Fournal of counseling Psychology 31, 3, 356.

[33] Lent, Robert W, Larkin, Kevin C, and Brown, Steven D, 1989. Relation of selfefficacy to inventoried vocational interests. Journal of vocational behavior 34,3 279-288.

[34] Margolis, Jane, Estrella, Rachel, Goode, Joanna, and Holme, Jennifer Jellison, 2008. Stuck in the Shallow End: Education, Race, and Computing. The MIT Press Cambridge, MA.

[35] Miura, Irene T, 1987. The relationship of computer self-efficacy expectations to computer interest and course enrollment in college. Sex Roles 16, 5, 303-311.

[36] Muenks, Katherine and Miele, David B, 2016. Students' TM thinking about effort and ability: The role of developmental, contextual, and individual difference factors. Review of Educational Research, 0034654316689328.

[37] Pausch, Randy, 2008. Alice: a dying man's passion. In Proceedings of the 39th SIGCSE technical symposium on Computer science education (Portland, OR, USA, 2008), ACM, 1352137, 1-1.

[38] Roberts, Eric S, Kassianidou, Marina, and Irani, Lilly, 2002. Encouraging women in computer science. ACM SIGCSE Bulletin 34, 2, 84-88.

[39] Scott, Allison, Martin, Alexis, Mcalear, Frieda, and Koshy, Sonia, 2017. Broadening Participation in Computing: Examining Experiences of Girls of Color. In Proceedings of the 2017 ACM Conference on Innovation and Technology in Computer Science Education (Bologna, Italy, 2017), ACM, 3059054, 252-256.

[40] Sherman, Dan, Darwin, Marlene J., Song, Mengli, Li, Yibing, and Statchel Suzanne, 2016. Evaluation Findings for the College Readiness Program on Student Outcomes. In American Educational Research Association, Washington, D.C.

[41] Steele, Claude M, 1997. A threat in the air: How stereotypes shape intellectual identity and performance. American Psychologist 52, 6, 613.

[42] Sweller, John and Cooper, Graham, 1985. The Use of Worked Examples as a Substitute for Problem Solving in Learning Algebra. Cognition and Instruction $2,1,59-89$.

[43] Trafton, John Gregory and Reiser, Brian J., 1993. The contributions of studying examples and solving problems to skill acquisition. In 15th Annual Conference of the Cognitive Science Society (Hillsdale, NJ, 1993), Lawrence Erlbaum Associates, Inc., 1017-1022.

[44] Wenger, Etienne, 1998. Communities of practice: Learning, meaning, and identity. Cambridge university press.

[45] Yun, Gi Woong and Trumbo, Craig W., 2000. Comparative Response to a Survey Executed by Post, E-mail, \& Web Form. Journal of Computer-Mediated Communication 6, 1 . 